\title{
A PRIORI ESTIMATES FOR ELLIPTIC EQUATIONS IN WEIGHTED SOBOLEV SPACES
}

\author{
LOREDANA CASO AND MARIA TRANSIRICO
}

Abstract. In this paper we prove some a priori bounds for the solutions of the Dirichlet problem for elliptic equations with singular coefficients in weighted Sobolev spaces.

Mathematics subject classification (2010): 35J25, 35B45, 35R05.

Keywords and phrases: Elliptic equations, a priori bounds, VMO-coefficients, weighted spaces.

\section{REFERENCES}

[1] R. A. Adams, Sobolev Spaces, Academic Press, New York (1975).

[2] V. Benci, D. Fortunato, Weighted Sobolev Spaces and the Nonlinear Dirichlet Problem in Unbounded Domains, Ann. Mat. Pura Appl, 121, 4 (1979), 319-336.

[3] A. Canale, L. Caso, Di Gironimo, Weighted norm inequalities on irregular domains, Rend. Accad. Naz. Sci. XL Mem. Mat., 16 (1992), 193-209.

[4] L. CASO, Regularity results for elliptic problems with singular data, J. Funct. Spaces Appl., 4 (2006), 243-259.

[5] L. CASo, Uniqueness results for singular elliptic problems, Bound. Value Probl., ID 98923 (2006).

[6] L. Caso, P. Cavaliere, M. Transirico, Solvability of the Dirichlet problem in $W^{2, p}$ for elliptic equations with discontinuous coefficients in unbounded domains, Matematiche (Catania), 57 (2002), 287-302.

[7] L. Caso, P. Cavaliere, M. Transirico, Uniqueness results for elliptic equations with VMOcoefficients, Int. J. Pure Appl. Math., 13 (2004), 499-512.

[8] L. Caso, P. Cavaliere, M. Transirico, An existence result for elliptic equations with VMOcoefficients, J. Math. Anal. Appl., 325 (2007), 1095-1102.

[9] L. Caso, M. Transirico, Some remarks on a class of weight functions, Comment. Math. Univ. Carolinae, 37 (1996), 469-477.

[10] F. ChiArenza, M. Frasca, P. Longo, Interior $W^{2, p}$ estimates for non divergence elliptic equations with discontinuous coefficients, Ricerche Mat., 40 (1991), 149-168.

[11] F. ChiAREnZA, M. Frasca, P. LONGO, $W^{2, p}$-solvability of the Dirichlet problem for nondivergence elliptic equations with VMO coefficients, Trans. Amer. Math. Soc., 336 (1993), 841-853.

[12] D. E. Edmunds, W.D. Evans, Elliptic and degenerate-elliptic operators in unbounded domains, Ann. Sc. Norm. Sup. di Pisa, 2 (1973), 591-640.

[13] M. Troisi, Su una classe di funzioni peso, Rend. Accad. Naz. Sci. XL Mem. Mat., 10 (1986), 141152.

[14] M. Troisi, Su una classe di spazi di Sobolev con peso, Rend. Accad. Naz. Sci. XL Mem. Mat., 10 (1986), 177-189.

[15] C. VITANZA, $W^{2, p}$-regularity for a class of elliptic second order equations with discontinuous coefficients, Matematiche (Catania), 47 (1992), 177-186.

[16] C. VitAnZA, A new contribution to the $W^{2, p}$-regularity for a class of elliptic second order equations with discontinuous coefficients, Matematiche (Catania), 48 (1993), 287-296.

[17] W. P. ZIEMER, Weakly Differentiable Functions, Springer, Berlin, 1989. 